\title{
Personal Growth Projects as a Means of Self-Development in Youth
}

\author{
Larisa Timasheva ${ }^{*}$ \\ Editorial Astrakhan State University, 414000 Astrakhan , Russia
}

\begin{abstract}
The article presents the results of research of students' self-development direction, describes the content of the tasks of self-development, identifies the possibility of using personal growth projects for self-development. Evidently, every third student considers self-development an important life task, and two out of three students set self-development goals. Students' desire for self-development is often conditioned by their environment. The majority of students set self-development goals based on one's spiritual views, the value of health and the value of other people. To demonstrate perseverance in solving problems of self-development they are hampered by weak development of strong-willed qualities and lack of motivation. The content of the tasks of self-development is volitional qualities, communicative skills, educational abilities, appearance and health. Conclusively, the effectiveness of using personal growth projects in setting and solving problems of self-development was determined.
\end{abstract}

Modern society needs a personality capable of selfdevelopment throughout entire life. According to V. I. Slobodchikov and E. I. Isayev, the process of selfdevelopment (transformation) is a journey of a man according to his goals, values and meaning of his existence. Transformation joins the processes of formation and establishment at certain stages of development, and becomes more dominant during adolescence. In adolescence an awareness of one's own individuality begins, life goals and plans appear, and a goal consciously constructing one's own life is set up [1].

The content aspect of the problem of the age transition is studied in the context of research on "development problems". By definition, P.G. Heymans, the task of development is "a period, or direction of development, during which an individual has the opportunity to prove or justify to a special jury or an audience that he is able to perform certain actions. This ability is due to the controlled and appropriate use of personal, public or material resources available. If the jury or audience is convinced that the individual really has this ability (to perform the action), he is given the right to act at his discretion, as if he really acquired this ability". The definition implies the following [2].

1. The task of development has criteria of success (not success itself); the individual is responsible for the successful fulfillment of the development task.

2. The result of successful resolution of the development task is a new ability (competence).

3 . There are signs that are associated with completing the task of development: feelings of pride or shame when using new abilities.

Numerous studies describe such problems of the development during adolescence as the formation of identity; awareness of themselves as being different from internalized parental images, emancipation from parents, awareness of the temporary tension of one's self, the projection of oneself into the future; formation of arbitrariness of behavior; anticipating the possible consequences of their actions and their behavior; establishment of responsibility as a subjective ability; development of the system of social relations; realization of the life plan; self-determination in the spheres of universal values; development of the "new body", physiological and psychological poloidity; development of abstract thinking; acquisition of interpersonal communication skills with peers; the emergence of new more independent relationships in the family; the development of a life philosophy, a system of values; setting the tasks of the future; self-awareness of the subject of self-determination, the emergence of individuality as a development of awareness of one's abilities and interests; the formulation of the tasks of self-development, self-improvement and selfactualization; search for cultural means of expression "feelings of adulthood"; search for the grounds for various moral elections and the development of personal moral principles; search for oneself, their difference from other people, search for one's own identity and uniqueness $[3,4]$

The idea of one's own actions to solve development problems gives an individual a certain degree of freedom in order to influence his own development.

This becomes relevant in connection with the changes taking place in the modern world.

There is a need to use in the development of personality new technologies that are oriented toward the development of a person's subjective position, capable of achieving a high level of motivation, development of independence, communicative abilities and creative thinking.

\footnotetext{
* Corresponding author: lavtim@mail.ru
} 
Among such technologies, the method of projects is being increasingly allocated now, which is actively used at various levels of training. At the heart of the project method lies the idea of the individual's orientation on the result, which is desirable to obtain for solving a particular problem [5]. For example, in education, method's essence is to stimulate students' interest in certain problems which involve the possession of certain knowledge and provide solutions through project activities, as well as apply practical knowledge and develop reflexive thinking [6].

In the context of our study, we are interested in project method as a means of motivating people to personal growth and self-realization of students [7].

In psychology, there are several approaches to the interpretation of the concept of "personal growth". From the point of view of the behavioral trend, personal growth presupposes the development of the sociopsychological competence of the individual, which means the development of a person's ability to interact effectively with people around him. Such personal growth is expressed in solving specific problems of mastering certain social and psychological skills and techniques, and interpersonal communication [8].

In humanistic models, the process of personal growth is understood as the basic condition for resolving psychological problems, the way for effective communication and human adaptation.

From the point of view of the existential direction, the essence of man is not specified initially, but is acquired by him in the process of individual search for his own unique identity. At the same time, from the existential point of view, there is not only a positive but also a negative potential in human nature. It depends on the personal choices of the person himself, for which he is personally responsible for [9-11].

According to S.L. Bratchenko only the basic law of personal growth should be discussed, which can be formulated as follows: "If there are necessary conditions, then the person actualizes the process of selfdevelopment, the natural consequence of which will be changes in the direction of his personal maturity. In other words, it is these changes - their content, direction, dynamics - that testify to the process of personal growth and can act as criteria for personal growth "[12]

The purpose of our research was to elucidate the possibility of using projects of personal growth in setting and solving problems of self-development. The study was conducted on the basis of the Federal State Budget Educational Institution of Higher Education "Astrakhan State University". A total of 56 students, aged 17 to 22 , enrolled in the faculties of psychology, history, philology and journalism took part in the study.

We used a questionnaire to determine the content of the tasks of students' self-development. The following research questions were formulated:

1. What are the goals and values of the subjects?

2. What personal qualities help them achieve their goals?

3. What do they want to change in their lives and themselves?
4. What do respondents experience when they fail and achieve their goals?

An analysis of the answers to the questionnaire showed the following results.

Students' answers to the question, "What are your life goals?" Were they ordered by the number of elections. The following sequence was obtained. $72 \%$ of respondents are targeted at creating a family; $64 \%$ are aimed at a professional career. Every second respondent $(50 \%)$ considers studying as the main life goal. Slightly less among life goals is the ownership of material things (45\%): house, apartment, car, expensive things, etc.

$30 \%$ consider their own development an important life goal. $29 \%$ of people dream of traveling, and $13 \%$ think that they should benefit society. $9 \%$ chose health and a healthy lifestyle as a life goal.

Answering about their educational goals, $47 \%$ of students connect studying with their own development. $30 \%$ of respondents believe that the acquisition of knowledge will help them find a job and be professionally successful. $13 \%$ are trying to learn for the sake of scholarship and other educational benefits. $4 \%$ of students study for the benefit of society, and $2 \%$ do it for the sake of the family, because their education is important to their parents. For $2 \%$ of the subjects, communication is the most important goal.

Next, we found out how determined the respondents are in achieving their goals. It turned out that only $43 \%$ of the subjects showed persistence in achieving their goals, the rest are not inclined to it.

Answering the question "What would you like to change in your life?", $38 \%$ of respondents said they want to change their place of residence, $27 \%$ - to start a family and communicate with friends, and $9 \%$ want to travel more often. $32 \%$ would like to increase their level of development, $18 \%$ - to improve their skills and $14 \%$ - to improve their academic performance. Every fifth person would like to correct mistakes made in the past (20\%), and $11 \%$ of respondents consider improving their health as an important change in their lives. As can be seen from the analysis of the answers, 64\% of respondents associate changes in their lives with changes in themselves, that is, they understand that to change their lives it is important to change themselves.

An analysis of the answers to the question about what exactly respondents want to change in themselves has revealed the following. $66 \%$ of respondents named individual qualities of the person (to become more patient, assiduous, strong-willed, sociable). They want to change the appearance of $50 \%$ (hair color, shape, facial features, etc.). To develop their intellectual abilities, $25 \%$ of responders want to study better, $7 \%$ - to master certain skills, for example, driving skills, cooking, playing an instrument, etc. $22 \%$ of the subjects want to change their physiological state and improve mental health.

At the same time, $66 \%$ of students wrote that internal resources can help them to change: $32 \%$ say they will be helped by such strong-willed qualities as perseverance, dedication, tenacity. Associate the opportunity to change with the motivation of $23 \%$ of the subjects, and $11 \%$ believe that they will be helped by the confidence in 
success. $44 \%$ of respondents hope for external resources: relatives, friends, acquaintances, money and luck.

Among the possible obstacles in self-development, $22 \%$ of respondents are external factors: lack of opportunities (16\%), lack of time (6\%). $72 \%$ of subjects state internal factors that impede self-development: laziness $(43 \%)$, uncertainty (20\%), difficulties with goalsetting $(9 \%)$,

Finding out what emotions and feelings are experienced by respondents with success or failure in solving problems of self-change, it was possible to establish the following. The majority of subjects (93\%) experience positive emotions, $3 \%$ of respondents have conflicting feelings ("I'm glad, but I'm sorry that could get better"), and $2 \%$ have negative experiences when achieving their goals. In the situation of unsuccessful self-development problems, $73 \%$ of respondents are disappointed, $13 \%$ have a feeling of insecurity, and $14 \%$ attribute lack of motivation to taking new actions to achieve their goals.

Thus, it was found that for every third student thinks self-development is an important life task, $64 \%$ set themselves the task of self-development. The content of the tasks of self-development of respondents are volitional qualities, communication skills, intellectual and other educational abilities, appearance, health, and skills and abilities related to the interests of the individual.

To study the features and direction of selfdevelopment, the personal growth research methodology developed by D. V. Grigoriev, I. V. Kuleshova, and P. V. Stepanov was used. The authors consider the concept of personal growth as a system of value relationships of subjects to various objects surrounding their reality, including themselves. The methodology also allows to determine the degree of stability of these relations in the structure of the personality, dividing them into situational, stable and fundamental [13].

On the situation and the instability of value relations of the individual can be said when a person manifests or does not manifest them depending on the specific life situation in which he finds himself. This is particularly clearly manifested in the transitional periods of a person's life.

Stable value relationships are reflected in a personal position and are characterized by a conscious perception of the world around and themselves in this world. Such a person, when getting into difficult life situations, tries to defend his own position, while demonstrating flexibility in his behavior and attitude to himself and others.

Fundamental value relations are characterized by consistency, and they practically do not change during life. Such people are considered bright and outstanding personalities. In extreme terms - it is fanatics, in which one value dominates all others.

In the context of our study, we studied the attitude of students toward knowledge, to other people and to themselves.

The formation of a value attitude to knowledge is the sociocultural task of education. However, for a genuine subject of educational or educational activity, this becomes the task of one's own development [14].
The value attitude to other people as a task of selfdevelopment presupposes the development of humanity, altruism and tolerance in various situations of communication. Humanity as a personal quality is represented by feelings of compassion, sympathy and manifested in communication through acts of assistance, support and involvement with others. Altruism is reflected in the position of a person to do unselfish deeds for the benefit of other people. The opposite of altruism is selfishness, which is characterized by a focus on satisfying first of all your own interests. Tolerance is seen as a willingness to accept other people and their opinions, even if they do not coincide with our own opinion. It assumes respectful attitude to other people and manifests itself in the ability to defend one's position without the humiliation of another person.

Attitude to himself was determined by the following parameters of personal growth:

- Attitude towards one's physical self is manifested in the pursuit of a healthy lifestyle and health improvement.

- The attitude towards one's inner Self (inner world) is reflected in the holistic acceptance of oneself, the strengths and weaknesses of one's personality.

- Attitude towards one's spiritual self implies the aspiration of the individual to independence, selfdetermination and self-realization.

As a result, we managed to find out the following. On the "attitude to knowledge" scale, only $13 \%$ of students have good results, which indicates their steady aspiration to acquire knowledge. They are active in the class, asking teachers many questions. In preparation for the seminars, additional material is being studied. They are sure that the success in the profession is directly related to the depth of knowledge and strive to receive it.

$62 \%$ of subjects demonstrate a situational-positive attitude, they study well, understand that the acquired knowledge is related to the future profession. But the position of the subject of educational and professional activity is not formed, so when they are trained they are more passive than active.

$25 \%$ of respondents have a situational-negative attitude to knowledge. This means that they do not need to acquire knowledge. They demonstrate a utilitarian attitude to the learning process and believe that the level and quality of the knowledge gained will not affect their life in the future. It is necessary to take into account that according to the results of the questionnaire, $14 \%$ of students would like to improve their academic performance, but only $2 \%$ are ready to change themselves for this. This means that for most students the development of a value attitude to knowledge is not a task of self-development.

Positive-value attitude to other people as a stable characteristic of the personality is characteristic of $16 \%$ of the subjects. They have the capacity for compassion, compassion, forgiveness, are always ready to help, show tolerant attitude towards others. $65 \%$ of respondents have a situational-positive attitude toward others. They realize the value of a person, but their kindness and charity is selective. Ready to help, but only when they are asked, while trying not to jeopardize their own wellbeing. They like to make gifts, but at the same time they 
are counting on a reciprocal gift in the depths of their hearts. In communication they tend to use stereotypes. The results of $17 \%$ of students correspond to the situation-negative attitude towards others. Unselfishness for them is equal to extravagance; good deeds must be rewarded. They are slopes to divide people into those who deserve a humane attitude and those who are not worthy of it. Steadily negative attitude towards others was revealed in $2 \%$ of the subjects.

By the parameter "attitude to their bodily self," $30 \%$ of the subjects expressed a desire to maintain a healthy lifestyle and resistance to harmful habits: smoking, drinking alcohol or doing drugs. $61 \%$ of students are characterized by a situational-positive attitude toward their health. They understand the importance of a healthy lifestyle, but believe that health does not require special efforts and therefore can sometimes afford alcohol and tobacco. Low results in $9 \%$ of subjects testify to the low value of health. Harmful habits are considered natural and completely acceptable. If we consider that only $22 \%$ of respondents want to improve their health by the results of the questionnaire, it turns out that half of the subjects are not going to make efforts to lead a healthy lifestyle and take care of their health.

High results on the parameter "attitude toward one's own spiritual self" were revealed only in $4 \%$ of students, which speaks of a stable-positive attitude towards one's inner world, unconditional acceptance of oneself, sincere manifestation of feelings, confidence in one's own strengths and capabilities.

$54 \%$ of subjects show a positive attitude toward their inner world. By accepting themselves, they may feel insecure and uncomfortable depending on the situation, afraid to find themselves in an embarrassing situation. They do not like to be alone with themselves, therefore they use music and films as substitutes for other people.

In $33 \%$ of respondents the attitude to their inner world is characterized as situationally negative. Such people are sure that their shortcomings are visible to others, so they try not to stand out. At the same time, loneliness for them is both painful and saving. Only in a few situations do they accept themselves with all the shortcomings. Wanting to like themselves and others, they often scold and criticize themselves.

Low results in $4 \%$ of students. Such people do not accept themselves and are considered ordinary people, unworthy of others' attention. They do not like the reflection in the mirror, any change is perceived as potentially unsuccessful. Once alone, they engage in self-discovery and soul-searching, experiencing a sense of guilt in front of themselves and others.

By the parameter "attitude towards one's spiritual self," $21 \%$ of respondents have good results. They treat themselves as the author and stewards of their own lives. For them, a sense of personal freedom is very important and for the sake of this feeling they are ready to resist external pressure. Therefore, they are capable of an independent and responsible choice. It is also important for them to find the meaning of their own lives and live "in accordance with their conscience".

In $73 \%$, a situational-positive attitude to one's spiritual self is revealed. These subjects consider themselves to be the manager of their life under favorable external circumstances. They like to feel free, but they are not ready to risk their well-being for the sake of freedom. Their life choices are pragmatic and calculated.

A situationally negative attitude toward one's spiritual self is characteristic of $6 \%$ of students. They try to avoid choice. If this fails, then they are ready to give up personal freedom in favor of a sense of peace and peace of mind. The need to dispose of their own lives causes them discomfort, so they try to find someone who took responsibility for their lives. Their failures are attributed to an unfavorable confluence of circumstances or actions of other people.

On the basis of the analysis, the following conclusions can be drawn. The setting of the tasks of self-development at the stage of adolescence, first of all, is conditioned by the value relation to one's spiritual self (94\%), therefore self-development is aimed at developing oneself as an independent author, subject of one's life. The second most important is the value of health, (91\%) and this determines the direction of selfdevelopment to preserve and improve one's health. In third place is the value attitude to others $(81 \%)$, which implies the development of the development of humanity, altruism and tolerance in communicating with other people. The fourth position in the system of value relations is occupied by knowledge (75\%), which is quite understandable in the sample of students. The inner world as a value is on the fifth place $(58 \%)$, which determines the direction of the individual to develop self-confidence and increase self-esteem.

Based on the statement of D.A. Leontiev that one of the components of personal growth is a system of meanings and life goals, the subjects were examined using the method "Smyslozhiznennye orientations" $[15,16]$.

The results showed that $58 \%$ of the subjects had high results on the "Goals in Life" scale. This, says that for them the definition of meaning is a vital task. This is expressed in the purposefulness of the individual, the certainty of plans for the future. The average figures indicate the desire of the individual to clearly structure life goals $(40 \%)$. This means that the definition of the meaning of life is not yet a task of self-development. Low results are typical for people who do not seek to set life goals $(2 \%)$.

Perceive their lives as $48 \%$ of the subjects filled with meaning. For $46 \%$ of respondents, life is interesting and emotionally saturated. $6 \%$ are not satisfied with their lives. $46 \%$ of students are satisfied with the results of their lives. They describe it as meaningful and productive. $50 \%$ noted partial satisfaction with life, and $4 \%$ speak of dissatisfaction with life. It is believed that they control their lives, freely make decisions and embody their ideas in life 60\%. Such people feel themselves to be the real creators of their lives.

With the help of Pearson's linear correlation, the relationship between the indicators of personal growth and the respondents' meaningful orientations has been calculated. Positive correlation at the level of statistical significance is also revealed between the value relation 
to knowledge and controllability of life $(r=0.318 ; \mathrm{p}=$ 0.01 ). In addition, there was a tendency to link such a parameter of personal growth as "attitude toward one's bodily self" and "locus of control-I" $(r=0.224 ; \mathrm{p}=$ 0.097); "Attitude toward one's mental self" and "life process" $(\mathrm{r}=0.250, \mathrm{p}=0.054)$; "Attitude to one's spiritual self" and "control locus is life" ( $r=0.250, p=$ 0.064).

Using the Spearman rank correlation, we examined how much the indicators of personal growth and meaningful orientations are related to the age of students. Positive correlation was found at the level of statistical significance between age and life performance $(\mathrm{r}=0.306, \mathrm{p} \leq 0.01)$, as well as between age and the parameter "locus of control - I" ( $r=0.309$; $\mathrm{p} \leq 0.01)$. Also, a negative correlation was found between the age of the subjects and the personal growth parameter "attitude toward one's spiritual self" $(\mathrm{r}=-0.225, \mathrm{p} \leq 0.05)$

For the purpose of selecting subjects to participate in projects of personal growth, the method of conversation was used. During the conversation, primary data were gathered about participants, about what they wanted to change in themselves and how much they wanted it. During the conversation with the respondents the following questions were asked; aimed at identifying individual development challenges.

- What do you want to change in yourself?

- What is your goal?

- What have you already done to achieve the goal?

- What happened?

- What else are you willing to do to achieve the goal?

As a result of the conversation, 10 people decided to take part in projects of personal growth. At the preproject stage, individual development plans were drawn up with each of them, the progress of which was recorded in diaries. Participants formulated the following tasks of self-development: increasing confidence, developing communication skills, self-presentation skills, planning their time, improving memory.

At the stage of project implementation, each participant conducted protocols, in which intermediate results were recorded, successes in improving themselves. The duration of the projects varied from two to six months. The reflexive stage involved discussing intermediate results and adjusting self-development plans, if necessary. At the end of the projects, feedback was used, which allowed one to understand how each participant managed to solve the problem of selfdevelopment using the project method. Conversations after the completion of the projects allowed one to find out that the projects of personal growth were successful; all participants were satisfied with the result. Most of them said that in the future they plan to use projects of personal growth for solving problems of selfdevelopment. Below are the statements of the three participants.

1. "Thanks to participating in the project of personal growth, I began to take a better attitude towards myself, gained a stable self-confidence, in my own strengths and capabilities. I think that in the future it will help me become a leader. "
2. "Thanks to the project of personal growth, in which I participated in order to improve my memory, I learned various ways of memorizing the text; I learned how to use them. Thanks to this, I became more organized, I began to study better."

3. "As a result of the project of personal growth, I became more confident in communicating with people. I got rid of the habit of coughing during a conversation, now I have a good diction. Now I'm not afraid to talk in an unfamiliar environment. I'm still working on myself. There is always something to strive for, and the exercises that we picked up with the psychologist, I will continue to perform."

Thus, we were convinced that projects of personal growth can be used for setting and solving problems of self-development.

\section{References}

1. V.I. Slobodchikov, E.I. Isaev, Psychology of Human Development (House Orthodox St. Tikhon Humanitarian University, Moscow, 2013)

2. P.G. Heymans, Conceptualization and operationalization of development tasks (MSU Publishing House, Moscow, 1995)

3. E. Erickson, Identity: youth and crisis. Trans. with English (Flint, Moscow, 2006)

4. G.A. Tsukerman, Psychology of self-development (Interprax, Moscow, 1995)

5. N.V. Matyash, Innovative pedagogical technologies: project training (Academy, Moscow, 2012)

6. T.V. Zelentsova, Man and modern society: the issues of pedagogy and psychology, 44-50, (2012)

7. N.R. Bityanova Psychology of personal growth (International Pedagogical Academy, Moscow, 1995)

8. N.R. Bityanova, The problem of self-development of personality in psychology: Analytical review (Flint, Moscow, 1998)

9. A. Yu. Kruglikova, Izvestiya SFU. Technical science 7, 104-105 (2005)

10. R. Frejger, D. Feydimen, Theories of personality and personal growth (OLMA PRESS, Moscow, 2004).

11. E.G. Surkova, Acmeology 3, 58-65, (2014)

12.S.L. Bratchenko, M.R Mironova, Psychological problems of self-realization of personality, 3-14, (1997)

13. P.V. Stepanov, Diagnosis and monitoring of the process of education in school (Academy, Moscow, 2003)

14. L.V. Timasheva, «East West» Association for Advanced Studies and Higher Education GmbH. Vienna, 76 - 81 (2014)

15. D.A. Leontyev, The test of meaningful orientations, (Sense, Moscow, 2000) 
16. D.A. Leontiev, Psychology of meaning: nature, structure and dynamics of semantic reality (Sense, Moscow, 2003) 